\title{
Location-Oriented Knowledge Management in a Tourism Context: Connecting Virtual Communities to Physical Locations
}

\author{
Christopher Lueg \\ Charles Darwin University, Darwin, Australia
}

lueg@cdu.edu.au

\begin{abstract}
Virtual communities have shown to be rich sources of knowledge if community members are sharing what they know. A look at virtual communities related to traveling in Australia suggests that often members are more than happy to share what they know about certain locations. In this paper, we outline, from a Location-oriented Knowledge Management (LoKM) perspective, the steps necessary to connect virtual communities to physical locations (and travelers exploring these locations). We will argue that this connection exceeds connections established by traditional web sites, such as privately operated sites or commercial travel guide-sites. We also highlight benefits for individual travelers, virtual communities and last but not least local businesses and other organizations.
\end{abstract}

Keywords: virtual communities, informing, tourism, PDA, WiFi, PlaceLab

\section{Introduction}

Location-oriented knowledge management (LoKM) is a novel research direction motivated by the observation that often utility and relevance of information is influenced by the physical location of the information seeker (Lueg \& Lichtenstein, 2003). For example, information regarding replacing the toner cartridge in a particular photocopying machine (a problem just too familiar to most office workers) is most relevant if the information seeker and the machine are co-located. In more general terms, we are interested in the role "location" may play as a distinct theme in knowledge management. LoKM draws from established research in mobile knowledge management (MobileKM) and ubiquitous computing (UbiComp), especially work in location-based computing and context-aware computing (e.g., Lueg, 2003).

Establishing sustainable links between those having knowledge and those seeking knowledge is another recurring theme in knowledge management. In the more general context of learning, knowledge is typically understood as being created within certain situations and at specific (virtual or physical) locations. Although knowledge itself can only be created dynamically in time (Newell, 1982), it is the being-in-the-world (Clark, 1997) that enables knowledge creation in the first place.

Material published as part of this journal, either on-line or in print, is copyrighted by Informing Science. Permission to make digital or paper copy of part or all of these works for personal or classroom use is granted without fee provided that the copies are not made or distributed for profit or commercial advantage AND that copies 1) bear this notice in full and 2) give the full citation on the first page. It is permissible to abstract these works so long as credit is given. To copy in all other cases or to republish or to post on a server or to redistribute to lists requires specific permission from the publisher at Publisher@InformingScience.org
Location-related knowledge is of particular interest in tourism settings when travelers are looking for information regarding sightseeing areas they are planning to visit. The traditional approach to informing about areas of interest is studying tourist guides and other related material. 
Quality tourist guides provide comprehensive information regarding the most interesting sites but they also have specific limitations. First, the content provided by traditional tourist guides tends to be fairly static. Second, traditional tourist guides tend to present information from a limited number of different perspectives typically corresponding to the number of authors.

Publishers of travel guides are now frequently updating their guides and provide travel-related information on their web sites. Additional offerings may include accessing guide content through WAP-enabled mobile phones (e.g., Lonely Planet) or web forums on the publisher's web site where travelers can converse with other travelers (e.g., Fodor's).

We believe that connecting virtual communities and geographic locations provides powerful options to complement traditional tourist guides and to address the issues described above. Virtual communities have shown to be rich sources of knowledge if community members are willing to share what they know (e.g., Lueg, 2003). Experiences with virtual communities related to traveling in Australia suggest that often members are more than happy to share what they know. Furthermore, connecting virtual communities and geographic locations is in line with the dramatic increase in connectivity and mobility that can be observed all over the world (see, for example, Rheingold, 2003).

We proceed as follows. First, we outline the benefits for the different stakeholders involved, namely travelers, virtual travel communities and local businesses as well as organizations. Next, we illustrate details of the connection between virtual communities and physical locations. Then, we address ways to finance the building of the infrastructure that required. Finally, we provide some closing remarks.

\section{Benefits of Connecting Virtual communities and Physical locations}

All stakeholders--travelers, virtual travel communities as well as local businesses and organizations--are likely to benefit from connecting virtual communities and physical locations. In this section, we discuss some of the benefits for each of the stakeholders. Technical details will be provided in the next section.

\section{Benefits for Travelers}

Traditional tourist guides tend to present information from a limited number of different perspectives. Now consider, as a rather simple example, overseas tourists coming to Sydney. One of the city's main attractions is Sydney Harbour and the "BridgeClimb", i.e., climbing the summit of Sydney Harbour Bridge. Views from the bridge are said to be stunning but opinions are divided whether the BridgeClimb is worth a fee of at least a hundred and fifty-five Australian dollars per adult; some say the experience is well worth the money whereas others suggest climbing one of the bridge's piers (and saving the money) would be the better choice. Opinions may also be divided regarding Sydney's nightlife. Some may prefer attending a classical performance at the Opera whereas others may be more interested in checking out backpacker watering holes. Visitors planning to spend some time at Sydney's Oxford Street may be interested in more explicit information than is typically provided in tourist guides addressing broader audiences.

Publishers of travel guides have started to address the diversity issue by publishing different guides targeting more specific tourist groups (compare, for example, The Rough Guide and Fodor's; the latter targets "traditional" tourists while the former aims at backpackers and other budget travelers. See Loker-Murphy and Pearce (1995) for a discussion of different tourist groups). 
Connecting travelers to virtual communities of Australia tourists would be a way to address the diversity problem in a far more flexible way. Virtual communities tend to represent a diverse range of interests and are also able to accommodate changing interests or interests that are not necessarily "typical" of a specific class of tourists.

The author's long term experiences with virtual tourism communities and other types of virtual communities of interest (Carotenuto et al., 1999), such as Usenet communities (e.g., Lueg, 2003), suggest that those participating in such communities are often more than happy to share their knowledge. Even if members are not able to answer questions directly they may be able to refer the information seeker to friends or other sites likely to provide the information sought. The sharing mentality is also evident from a myriad of personal travel web sites set up to share experiences (see also Brown \& Chalmers, 2003).

A connection between travelers and virtual communities would provide travelers with a communication channel allowing them to feed information back to the virtual community (see below). Furthermore, such a communication channel may also be used to connect them to their friends and families back home.

\section{Benefits for Virtual Communities}

Virtual communities would benefit as experiences suggest that quite a few travelers would feed some of their experiences back to the community. Information could range from simply updating out-dated information and adding new information to reporting diverging experiences.

Furthermore, it would be possible to further expand the idea of having travelers follow dynamically created tours proposed by Davies, Cheverst, Friday, \& Mitchell (2002). Their idea was to re-use movement data that could be collected when device-carrying travelers explore an area. This data could then be used to define "most popular" tours or "tours by famous people". The community connection proposed in this paper would allow community members to propose specific tours based on their knowledge, interests and past experiences. Inquiries of this kind are actually quite popular in travel-related online communities.

Establishing a connection between virtual travel communities and actual travelers offers endless opportunities for interaction. An architecture fan from Germany might describe a tour covering different housing styles to be found in Sydney. An Australian World War II veteran might compile a Darwin tour covering sites of military action during World War II whereas a biologist from England interested in tropical flora might create a tour covering the rain forest in the Botanical Gardens and the swamps near Darwin's Eastend. A pub fan might even compile a sight-seeing tour coming along her favorite pubs every now and then. Last but not least, residents of Darwin may feed their views into the system to show travelers what they think is special about their home town, or . Even the idea of a "most popular" tour mentioned earlier could be realized by feeding comments back to the community the tour proposal originated from.

\section{Benefits for Local Businesses and Organizations}

The technical infrastructure required would be difficult to implement without support from local businesses and other organizations. There are, however, several ways of developing business models leading to sustainable support for connecting virtual communities to physical locations (and, of course, travelers exploring these locations).

Culturally-oriented business models could support provision of navigational devices helping tourists explore certain aspects of an area that would be difficult to perceive or comprehend otherwise. This could mean, among other things, educational tours through time (e.g., Davies et al., 2002). Overseas tourists coming to Sydney, for example, may not be aware that the area the city 
is built on used to be Aboriginal land. A navigational device sensing and visualizing related information might help tourists understand this aspect of the city and its history. Visitors coming to Darwin are rarely aware of the Japanese bomb raids the city experienced during World War II. Again, a navigational device visualizing information clouds surrounding sites of military action might help visitors explore this aspect of Darwin's past. Such efforts could be supported by tourism boards, historical societies, government, and other parties interested in providing an educational "informational lens" on an area.

More business-oriented aims include novel ways to attract customers. Pubs, coffee shops and other tourism-oriented businesses depend on customers finding their way to their door-steps. Offering (often free) wireless Internet access during consumption is an idea to attract customers pursued by companies such as Starbucks in the U.S. and Delifrance in Australia. In addition to this more passive mode of attracting customers, businesses could use information beacons in a more active way by "broadcasting" information regarding sales, happy hours, special food offers, etc. Shops not located at the main tourist streets or less exposed to the public for other reasons (e.g., first floor instead of basement) may beacon information to attract customer attention.

Businesses could beacon information targeting specific interests and clients' could scan the invisible information cloud for such information, helping visitors navigate the environment more efficiently and helping them make the most out of their stays.

Customers willing to reveal their identities and/or interests may also be targeted by using dynamic advertising (e.g., personalized advertising as seen in the movie "Minority Report"). Mankins (2002) discusses dynamically adjusted digital advertisements that are influenced by an area's demographics. An example of dynamic advertising would be taxis coming from Sydney's CBD changing their advertising when approaching Oxford Street or King's Cross.

\section{Connecting Virtual Communities and Physical Locations}

Rapid technical progress in the area of portable computers (processing power, storage capacity, size, and last but not least price) allows for a number of ways to connect virtual communities and physical locations (and travelers exploring these locations):

\section{Community Content Cached Locally (Incl. Download from the Web)}

The technically least demanding solution would be downloading relevant content from the web and caching it for later use. Nowadays, off-the-shelf laptops provide more than enough storage capacity. While traveling, downloading additional content can be done in Internet cafes or via ondemand Internet access. Tools supporting the download of whole web sites are available.

Although lacking real time interaction with content contributors, the caching solution already complements traditional tour guides by providing opportunities to consult with a variety of perspectives and experiences.

A weakness of the caching solution is that tourists themselves have to associate content and location as the solution would not exhibit any notion of "location-orientation" (in the sense that location is determined and used automatically when retrieving relevant content).

\section{Cached Community Content Plus Location Orientation.}

A technically more advanced solution would be augmenting the caching solution to a locationoriented solution. Then, association of content and location can be done automatically (e.g., Mankins, 2002) and location-oriented content retrieval methods, such as Voelker and Bershad (1994) or Takahashi (2000), would take the association burden off the user's shoulders. 
Adding location-orientation can be accomplished in a number of different ways:

\section{The user keeps updating the current location}

This approach may work satisfactory if the user tends to stay at certain well-defined locations but it does not appear to be appropriate if the user keeps moving around (as travelers tend to do--see Loker-Murphy \& Pearce 1995 for details). It may also be difficult for the user to provide location data in specific formats that may be required by databases and retrieval mechanisms (e.g., location data in GPS format).

\section{Global positioning system (GPS)}

Incorporation of a GPS receiver unit can provide location information based on Differential Global Positioning System (DGPS) techniques. However, the GPS approach requires that enough satellites are within unrestricted view. This implies certain limitations in cities, mountains, forests, and of course indoors (see, for example, Cheverst, Davies, Mitchell, Friday, \& Efstratiou, 2000).

Another major disadvantage in the context of this paper is that GPS provides "pure" geographical information. The GPS system does not yet support transmission of additional information that might be useful at a particular location.

\section{WiFi positioning}

This refers to a grassroots approach to creating a global WiFi positioning system based on IEEE 802.11b (Airport/WiFi/WaveLAN) based access points (see Schilit et al., 2003 for details). This approach is based on rather simple wireless access points beaconing a Basic Service Set Identifier (BSSD) plus a locally kept database listing the physical location of BSSD. Triangulating signal strengths plus looking up BSSD in the database gives the current location. Feasibility of this approach had been demonstrated at the UbiComp 2003 conference.

In the context of this paper, the main advantage of using WiFi positioning is that it allows relatively inexpensive coverage of areas that would not be covered otherwise (e.g., GPS and/or GSM unavailable or usage too expensive).

Furthermore, basic access points required by WiFi positioning (see, for example, Flickenger, 2002 for technical details) could be used to beacon additional information that would be intrinsic to a specific location.

\section{Other positioning systems, such as GSM based systems}

GSM-based services can be used in urban and selected rural areas. However, travelers like to explore remote areas (e.g., Loker-Murphy \& Pearce, 1995) and GSM is unavailable in most parts of remote Australia. Accordingly, we are focusing on approaches that do not rely on such an infrastructure.

\section{Full Wireless Internet Access (e.g., Based on IEEE 802.11b)}

First of all, wireless Internet access does not provide location data by itself. In any case, additional information is required to determine the user's current location.

Furthermore, the basic assumption underlying this paper (and most of the work referenced) is that there won't be broad (full) wireless coverage in the near future. Wireless Internet access can be assumed to be available in major population centers and, via GSM-based services, in GSMcovered areas but in Australia these areas are more the exception than the rule. 
Nevertheless, fully connected areas can be used to download (and cache) the latest community content as well as to upload feedback and other communication, such as email.

\section{Covering the Environment}

In the previous section, we outlined that in addition to complementing standard positioning approaches, WiFi positioning allows relatively inexpensive positioning in areas that would not be covered otherwise (e.g., GPS and/or GSM unavailable or usage too expensive). Furthermore, access points (AP) could be used to beacon additional information that would be intrinsic to a specific location.

WiFi positioning within an area requires dense coverage with wireless AP, allowing clients to triangulate their current position. As mentioned before, AP may be based on relatively inexpensive hardware and software. Internet connectivity -although desirable- is not required.

Accordingly, it would be relatively inexpensive to beacon up popular tourism locations. Especially geographically rather small areas of particular interest to tourists, such as Darwin's CBD, Downtown Zurich between Main Station and Lake Zurich or Sydney's Darling Harbour and The Rocks would require only a few dozen AP covering an area of up to a hundred meters each. It is reasonable to assume that the range of AP will increase over the next few years which means even less AP would be required.

By focusing on smaller areas, immense upfront costs associated with mapping large areas would be avoided (see, for example, costs involved in mapping the inner city of Helsinki, e.g., Linturi, Koivunen, \& Sulkanen, 2000).

Even at more remote locations, self-sustaining and maintenance-free AP could be used to complement or replace GPS-based services. As full wireless connectivity is not required, it would be easy to cover areas, such as Darwin's EastEnd or the Fog Dam Reservoir. Unlike approaches requiring full Internet access, WiFi positioning can be used to beacon up even remote areas, such as tourism spots in Kakadu National Park.

As already indicated in previous sections, beaconing up an area involves two main parts:

\section{The "Beaconing Up" Itself}

Increasingly, areas of interest to tourists are wired up anyway. WiFi enthusiasts (e.g., Sydney Wireless or Darwin Wireless) are working on wiring up their cities; coffee shops like Starbucks in the U.S. or Delifrance in Sydney are already providing wireless internet access points to be used by customers; other businesses and organizations may join sooner or later. These AP however are providing full internet access which exceed what is required for WiFi positioning. It would be easy to augment these access points to beaconing location information.

Progress in this direction can be sustained by developing business models encouraging local organizations and businesses to provide at least basic access points beaconing location information.

\section{Provision of Navigational or Other Devices Making Use of the In- formation Provided}

Navigation devices in the tradition of Cyberguide (Abowd et al., 1997) or GUIDE (Cheverst et al., 2000) allow tourists to query AP for location information. Davies et al. (2002) discuss using the wireless network they installed for additional services. We are interested in using AP for retrieving location-specific information.

Navigation devices could be rented out commercially given that there is some sustainable business model underlying the rental process. Alternatively, local tourism boards might support pro- 
vision of navigation devices as the invisible information layer accessible through these devices can be used for a number of tourism-related purposes.

Increasingly, tourists are bringing along their own devices anyway. Inquiries on tourism-related Internet discussion boards regarding wireless and other internet access points indicate that it is no longer unusual for tourists to bring their own devices.

Business travelers often carry laptops but they are less likely to be interested in exploring a city which is the assumption underlying this work.

Privacy concerns are not necessarily an issue as WiFi positioning and reception of information does not require users to reveal their identity. Rather, WiFi positioning is based on passive reception of information. Using WiFi-positioning to access location-relevant information via the web (e.g., Takahashi et al. 2000), however, would require revealing some information (e.g., the user's current position).

\section{Concluding Remarks}

In this paper, we discussed connecting virtual communities and physical locations from a location-oriented KM perspective. While we focused on tourism settings it should be clear that there are numerous other settings in which such connections would benefit stakeholders. Linking consultants 'on the road' to their respective communities of practice (Wenger, 1998) would be an example of a similar setting situated in the world of business rather than tourism.

The main points regarding connecting virtual communities and physical locations are a) that the connection is feasible using currently available technology, and b) that all stakeholders involved would benefit. It seems it would be tourists who benefit most as they would be able to access a range of different opinions and perspectives while actually involved in exploration activities. Considering Rheingold's investigation Smart Mobs, however, this and other proposals might be just a first tiny step in a tidal wave of change in information access patterns, and those businesses who jump on the train first might gain competitive advantages as they were able to gain experiences without being in turmoil.

From a research point of view, establishing the connection between virtual communities and physical locations would enable a range of research opportunities from questions relating to interactive real-time marketing to using mobile devices for exploring specific perspectives on the environment.

Please note that one of the technological and, in particular, ideological backbones of the research outlined in this paper is the PlaceLab initiative jointly pursued by a number of U.S. universities and research labs. I believe that the bottom-up philosophy underlying the PlaceLab project has a lot to offer to settings in Australia. A few of them were explored in this paper.

\section{Acknowledgments}

David McDonald and Michael Twidale provided valuable input.

\section{References}

Abowd, G.D., Atkeson, C.G., Hong, J., Long, S., Kooper, R., \& Pinkerton, M. (1997). Cyberguide: A mobile context-aware tour guide. Wireless Networks, 3 (5), pp. 421-433. 
Brown, B. \& Chalmers, M. (2003). Tourism and mobile technology. Proceedings of the Eighth European Conference on Computer Supported Cooperative Work, September 2003, Helsinki, Finland, pp. 335354. Kluwer Academic Publishers.

Carotenuto, L., Etienne, W., Fontaine, M., Friedman, J., Newberg, H., Muller, M., Simpson, M., Slusher, J., $\&$ Stevenson, K. (1999). CommunitySpace: Toward flexible support for voluntary knowledge communities. Proceedings of the Workshop "Changing Places", London, UK.

Cheverst, K., Davies, N., Mitchell, K., Friday, A., \& Efstratiou, C. (2000). Developing a context-aware electronic tourist guide: Some issues and experiences. Proceedings of the Annual ACM SIGCHI Conference on Computer-Human Interaction, The Hague, The Netherlands, pp. 17-24.

Clark, A. (1997) Being there. Cambridge, MA, USA: MIT Press. A Bradford Book.

Darwin Wireless. URL http://www.darwinwireless.com

Davies, N., Cheverst, K., Friday, A., \& Mitchell, K. (2002). Future wireless applications for a networked city: services for visitors and residents. IEEE Wireless Communications, February, pp. 8-16.

Flickenger, R. (2002). Building wireless community networks. Sebastopol, CA, USA: O'Reilly \& Associates.

Fodor's. URL http://www.fodors.com

Linturi, R., Koivunen, M., \& Sulkanen, J. (2000). Helsinki Arena 2000 - Augmenting a real city to a virtual one. In Digital Cities, Lecture Notes in Computer Science, Volume 1765, pp. 83-96. Springer-Verlag.

Loker-Murphy, L. \& Pearce, P.L. (1995). Young budget travelers: Backpackers in Australia. Annals of Tourism Research, 22 (4), 819-843.

Lonely Planet. URL http://www.lonelyplanet.com

Lueg, C. (2002). Looking under the rug: Context and context-aware artifacts. International Journal of Cognition and Technology, 1 (2), 287-302.

Lueg, C. (2003). Knowledge sharing in online communities and its relevance to knowledge management in the e-business era. International Journal of Electronic Business, 1 (2), 140-151. ISSN 1470-6067.

Lueg, C. \& Lichtenstein, S. (2003). Location-Oriented Knowledge Management - A workshop at the Fourteenth Australasian Conference on Information Systems (ACIS 2003), 26-28 November 2003, Perth, WA, Australia.

Mankins, M. (2002). The digital sign in the wired city. IEEE Wireless Applications, February, pp. 54-58.

Newell, A. (1982) The knowledge level. Artificial Intelligence, 18, 87-127.

Rheingold, H. (2003). Smart mobs: The next social revolution. Perseus Publishing.

Schilit, B., LaMarca, A., Borriello, G., Griswold, W., McDonald, D., Lazowska, E., Balachandran, A., Hong, J., \& Iverson, V. (2003). Ubiquitous location-aware computing and the "Place Lab" initiative. The First ACM International Workshop on Wireless Mobile Applications and Services on WLAN, September 19, 2003, San Diego, CA, USA.

Sydney Wireless. URL http://www.sydneywireless.com

Takahashi, K., Yokoji, S., \& Miura, N. (2000). Location oriented integration of Internet information - Mobile info search. In Digital Cities, Lecture Notes in Computer Science, Volume 1765, Springer-Verlag, March 2000.

Voelker, G.M. \& Bershad, B.N. (1994). Mobisaic: An information system for a mobile wireless computing environment. Workshop on Mobile Computing Systems and Applications, pp. 185-190, December 1994. Also appeared as a book chapter in Mobile Computing, published by Kluwer Academic Publishers, 1996.

Wenger, E. (1998). Communities of practice: Learning, meaning, and identity. Cambridge University Press. 


\section{Biography}

